\title{
Seleção fenotípica e assistida por marcadores moleculares de famílias de feijoeiro-comum com alta produtividade
}

\author{
Helton Santos Pereira(1), João Bosco dos Santos ${ }^{(2)}$, Thaís Paula de Souza ${ }^{(2)}$ e Igor Almeida Lima ${ }^{(2)}$
}

\begin{abstract}
(1)Embrapa Arroz e Feijão, Caixa Postal 179, CEP 75375-000 Santo Antônio de Goiás, GO. E-mail: helton@cnpaf.embrapa.br (2)Universidade Federal de Lavras, Departamento de Biologia, Caixa Postal 37, CEP 37200-000 Lavras, MG. E-mail: jbsantos@ufla.br, thaisps@hotmail.com, igorlimalmeida@yahoo.com.br
\end{abstract}

Resumo - O objetivo deste trabalho foi selecionar famílias de feijoeiro-comum, com alta produtividade de grãos, por meio de seleção fenotípica e de seleção assistida por marcadores moleculares (SAM). Foram avaliadas 394 famílias, de quatro populações, e seus seis genitores, no Município de Lavras, em dois experimentos: um na geração $F_{3: 4}$, na safra das águas de $2005 / 2006$, em látice simples $20 x 20$; e outro na geração $F_{3: 5}$, na safra da seca de 2006, em látice triplo 20x20. Foram estimados parâmetros genéticos e fenotípicos, e foi realizada a genotipagem das famílias, com marcadores microssatélites associados a QTL controladores da produção de grãos, previamente identificados. Também foram realizadas análises de associação por marcas simples, entre os marcadores e a produção de grãos, e foi obtido um índice para a SAM. A ampla variabilidade entre famílias e as altas estimativas de herdabilidade possibilitaram obter elevados ganhos com a seleção fenotípica. Os marcadores explicaram pequena percentagem da variação fenotípica e apresentaram alta interação QTL $\mathrm{x}$ ambiente e QTL x população. A SAM gerou baixos ganhos e a coincidência de famílias selecionadas pelas duas metodologias foi baixa, o que evidencia, neste caso, a ineficiência da SAM, principalmente pela pouca disponibilidade de marcadores ligados a QTL.

Termos para indexação: Phaseolus vulgaris, QTL, locos de características quantitativas, associação por marcas simples, ganho genético, herdabilidade, microssatélites.

\section{Phenotypic and marker-assisted selection of common bean families with high grain yield}

\begin{abstract}
The objective of this work was to select common bean families with high grain yield, using phenotypic and marker-assisted selections (MAS). Evaluations were made for 394 families of four populations and their six parents, in Lavras county, Minas Gerais, Brazil. Two field experiments were conducted: one in the $\mathrm{F}_{3: 4}$ generation, in the rainy season of 2005/2006, using a 20x20 simple lattice design; and other in the $\mathrm{F}_{3: 5}$ generation, in the dry season of 2006, using a 20x20 triple lattice design. Genetic and phenotypic parameters were estimated, and the families were genotyped with microsatellite markers for grain yield quantitative trait loci (QTL), that had been identified previously. Simple marker association analysis was performed between markers and grain yield, and an index was estimated for MAS. The high variability between families and the heritability estimates made high genetic gains possible through phenotypic selection. The markers explained a small percentage of phenotypic variation, and presented high QTL $\mathrm{x}$ environment and QTL x population interactions. The MAS achieved small gains, with low coincidence of families selected by both methodologies, showing, in this case, that the MAS inefficiency was mainly due to the low number of available markers.
\end{abstract}

Index terms: Phaseolus vulgaris, QTL, quantitative trait loci, simple marker association analysis, genetic gain, heritability, microsatellites.

\section{Introdução}

Em programas de melhoramento de feijoeirocomum, grande atenção deve ser dada à seleção de famílias segregantes promissoras, que darão origem a novas linhagens e cultivares. Se possível, a seleção deve ser realizada nas primeiras gerações segregantes, para possibilitar que, desde o início, os esforços estejam dirigidos na avaliação das melhores famílias, com economia de tempo e recursos.

A seleção fenotípica é realizada por meio de técnicas clássicas de melhoramento e apresenta comprovada eficiência, refletida pelos contínuos ganhos genéticos em produtividade, obtidos ao longo de vários anos, em 
várias culturas. No feijoeiro-comum, estima-se que esses ganhos sejam de $1,6 \%$ ao ano (Matos, 2005). Porém, como o progresso genético é contínuo, o nível de produtividade vem aumentando e as diferenças a serem detectadas são cada vez menores. Com isso, novas ferramentas devem ser estudadas para aumentar a eficiência dos programas de melhoramento.

Os marcadores moleculares podem ser empregados para auxiliar programas de melhoramento, e inúmeros trabalhos vêm sendo realizados com esse propósito (Yousef \& Juvick, 2001; Mendonça et al., 2002; Faleiro et al., 2004).

No processo de seleção quanto a caracteres quantitativos, como a produção de grãos, em que a influência do ambiente é maior, espera-se maior contribuição dos marcadores moleculares, em razão das dificuldades envolvidas no processo de seleção fenotípica (Borém \& Caixeta, 2006). Para que as informações de marcadores moleculares sejam úteis no processo seletivo, a primeira etapa é a identificação de marcadores associados aos QTL ("quantitative trait loci") envolvidos no controle do caráter de interesse. Esses marcadores podem ser utilizados na seleção de genótipos superiores. Embora inúmeros QTL já tenham sido identificados para vários caracteres na maioria das culturas de grande importância, inclusive alguns para a produção de grãos em feijão-comum (Faleiro et al., 2003; Melo et al., 2004; Rodrigues, 2004; Teixeira, 2004; Blair et al., 2006b), são poucos os relatos de sucesso da incorporação dessas informações ao processo seletivo e na obtenção de novas cultivares (Yousef \& Juvick, 2001; Moreau et al., 2004; Bernardo, 2008).

A seleção assistida por marcadores (SAM), em relação aos caracteres quantitativos, é eficiente quando a herdabilidade do caráter é baixa e quando os marcadores explicam alta proporção da variância aditiva dos caracteres (Lande \& Thompson, 1990). Como a produção de grãos é um caráter que apresenta baixa herdabilidade e é controlado por grande número de genes de pequeno efeito, para se identificar um grupo de marcadores que explique uma maior proporção da variação fenotípica, é necessário utilizar grande número de marcadores ligados a QTL, dispersos no genoma (Lande \& Thompson, 1990; Bernardo, 2002; Xu \& Crouch, 2008).

Para incorporar informações dos marcadores moleculares aos programas de melhoramento, devem ser realizados trabalhos com a seleção assistida por marcadores moleculares (SAM), em condições comuns às de programas de melhoramento que visem à obtenção de linhagens mais produtivas. Nesses programas, normalmente, as famílias a serem selecionadas são oriundas de populações com alta produtividade, obtidas a partir do cruzamento de linhagens elite e cultivares já melhoradas, e que apresentam, portanto, menor variabilidade do que em estudos básicos de mapeamento.

O objetivo deste trabalho foi selecionar famílias de feijoeiro-comum com alta produtividade de grãos, oriundas de diferentes populações elite, por meio da seleção fenotípica e da assistida por marcadores microssatélites ligados a QTL que controlam a produção de grãos.

\section{Material e Métodos}

Foram utilizadas sementes da geração $\mathrm{F}_{3}$ de quatro populações, obtidas e selecionadas por Pereira et al. (2007), com base em análise dialélica eno polimorfismo dos genitores para marcadores microssatélites. Esses microssatélites foram identificados por Rodrigues (2004) e Teixeira (2004) como ligados a QTL que controlam a produção de grãos. A população 1 apresentou alta produtividade e alta capacidade específica de combinação (CEC), e originou-se do cruzamento entre as linhagens RCI-10 e Z-9, que mostraram maior capacidade geral de combinação (CGC). A população 2 originou-se do cruzamento entre a linhagem RCI-10 e a cultivar BRSMG Talismã e apresentou: alta produtividade, um genitor com alta CGC e polimorfismo para os marcadores moleculares BM-152 e BM-156. A população 3 originou-se do cruzamento entre as linhagens MAI-18.13 e Z-9 e apresentou: produtividade intermediária, um genitor com alta CGC e o maior número de marcadores polimórficos (BM-152, BM-156, U-77935 e X-74919). A população 4 originou-se das linhagens Batatinha e B1 - bem divergentes fenotipicamente -, e mostrou polimorfismo entre os genitores para os marcadores BM-156, BM-143 e BM-175. Com exceção da linhagem Batatinha, todas as linhagens usadas são linhagens elite, obtidas pelo Programa de Melhoramento de Feijoeiro da Universidade Federal de Lavras.

As sementes da geração $F_{3}$ de cada população foram semeadas em campo e, por ocasião da colheita, 
coletaram-se sementes de 300 plantas, individualmente, em cada população. As sementes de cada planta deram origem a uma família, num total de 1.200 famílias $\mathrm{F}_{3: 4}$. Posteriormente, foram eliminadas as famílias com grãos fora do padrão comercial "carioca", o que fez com que restassem 100 famílias da população 1 ; 100 da população 2; 100 da população 3; e 94 da população 4 .

Os tratamentos foram constituídos pelas 394 famílias e pelos seis genitores envolvidos na obtenção dessas populações, e foram avaliados em dois experimentos. $\mathrm{O}$ primeiro foi conduzido com famílias $\mathrm{F}_{3: 4}$, na safra das águas, no ano de 2005/2006, em delineamento de látice simples 20×20, com parcelas constituídas por uma linha de $1 \mathrm{~m}$ e espaçamento de $50 \mathrm{~cm}$ entrelinhas, tendo sido semeadas 15 sementes por metro linear. O segundo experimento foi conduzido com famílias $\mathrm{F}_{3: 5}$, na safra da seca, no ano de 2006, em delineamento de látice triplo $20 \times 20$, com parcelas de uma linha de $2 \mathrm{~m}$, com espaçamento e quantidade de sementes por metro linear idênticas às do primeiro experimento. Quatro famílias utilizadas no primeiro experimento não produziram sementes suficientes para montar o segundo experimento e foram substituídas por quatro cultivares, para manter o delineamento látice. Essas famílias e cultivares não foram utilizadas na análise conjunta. As avaliações foram realizadas no Município de Lavras, Minas Gerais, no campo experimental da Ufla.

$\mathrm{Na}$ semeadura, a adubação foi feita com $300 \mathrm{~kg} \mathrm{ha}^{-1}$ de 8-28-16 (N, $\left.\mathrm{P}_{2} \mathrm{O}_{5}, \mathrm{~K}_{2} \mathrm{O}\right)$, e $150 \mathrm{~kg} \mathrm{ha}^{-1}$ de sulfato de amônio foram aplicados, em cobertura, 20 dias após a emergência. Os demais tratos culturais foram os comuns ao cultivo do feijoeiro (Paula Júnior et al., 2008), inclusive as irrigações complementares por aspersão, quando necessário. Não foram aplicados inseticidas nem fungicidas. Avaliou-se a produtividade de grãos, medida em gramas por parcela, com posterior transformação para quilogramas por hectare.

Realizaram-se as análises de variância por experimento e conjunta, tendo sido os efeitos de tratamentos considerados como aleatórios e os de safra como fixo, por meio do aplicativo MSTAT-C (Freed et al., 1991). A partir dessas análises, foram obtidas as esperanças dos quadrados médios, conforme recomendações de Vencovsky \& Barriga (1992) e Ramalho et al. (2000), e foram estimadas as variâncias genéticas e da interação tratamentos por ambientes, além da herdabilidade, de seus limites de confiança, e o ganho esperado com a seleção (Knapp et al., 1985; Ramalho et al., 1993).

Para as análises com marcadores moleculares microssatélites, foi realizada a extração de DNA das famílias das populações 2 e 3 , que totalizaram 200 famílias, e também reações de PCR, por meio de um procedimento semelhante ao utilizado por Teixeira et al. (2005), com os microssatélites identificados por Pereira et al. (2007), como polimórficos para cada população (quatro marcadores para a população $3 \mathrm{e}$ dois para a população 2), e ligados a QTL responsáveis pela produtividade de grãos (Rodrigues, 2004; Teixeira, 2004). Como o objetivo do trabalho foi testar a seleção com marcadores em uma situação semelhante à que ocorre em um programa de melhoramento, foram selecionadas as duas populações mais promissoras para a análise com marcadores moleculares, que foram a 2 e 3 , por terem apresentado bom desempenho em produtividade, pelo número de marcadores polimórficos e por terem se originado de quatro genitores diferentes.

Inicialmente, foram realizadas as análises de associação por marcas simples (AAMS), por meio de comparação entre médias, para a certificação de que os marcadores utilizados realmente estavam ligados aos QTL controladores da produtividade de grãos nas populações, conforme Schuster \& Cruz (2004). Assim, realizou-se a análise de variância da produtividade de grãos das famílias, de cada população, para cada marcador, e foram obtidas as probabilidades de os marcadores estarem ligados a QTL (valores P). Também foi estimado o coeficiente de determinação, a partir das somas de quadrados de genótipos e total.

A partir das AAMS, foi construído um índice de seleção, por meio de comparação entre médias, para as famílias da população 3 , que foi baseado na informação dos marcadores microssatélites polimórficos e nas médias fenotípicas das famílias, semelhantemente ao procedimento utilizado por Stromberg et al. (1994). Nesse índice, cada marcador foi considerado como se fosse uma característica, em um índice de seleção convencional. O vetor com os valores do índice I, para cada uma das famílias, foi calculado da seguinte maneira: $\mathrm{I}=\mathrm{MQ}$, em que: $\mathrm{M}$ é a matriz com $\mathrm{f}$ linhas (número de famílias) e $\mathrm{m}$ colunas (número de marcadores), em que o valor de uma família para um marcador foi a produção média de todos os indivíduos 
que possuíam o mesmo genótipo para esse marcador; $\mathrm{Q}$ é o vetor com $\mathrm{m}$ linhas (número de marcadores), em que cada valor é o do teste F para genótipos obtido na análise de associação por marcas simples (Stromberg et al., 1994).

Foram realizadas as análises de regressão múltipla "stepwise", com os marcadores de cada população, pelo uso do programa GQMOL versão 2005.6.1 (Cruz \& Schuster, 2004), para a obtenção das estimativas de $\mathrm{R}_{\mathrm{m}}{ }_{\mathrm{m}}$ (coeficiente de determinação), utilizadas na estimativa do ganho esperado com a SAM. Esse ganho, para cada safra e para a análise conjunta, foi calculado conforme Ramalho et al. (1993): $\mathrm{GS}_{\mathrm{m}}=\mathrm{ds}_{\mathrm{m}} \times \mathrm{R}_{\mathrm{m}}^{2}$, em que: $\mathrm{ds}_{\mathrm{m}}$ é o diferencial de seleção, ou seja, a diferença entre a média das famílias selecionadas pelo índice dos marcadores e a média geral das famílias, da população $\mathrm{p}$; e $\mathrm{R}_{\mathrm{m}}^{2}$ é o coeficiente de determinação, estimado nas análises de regressão múltipla "stepwise".

\section{Resultados e Discussão}

A análise de variância conjunta mostrou a existência de variabilidade genética entre os genitores e as famílias de cada população (Tabela 1). As interações de famílias de cada população x safras evidenciaram a resposta diferencial das famílias nas safras. Também foram observadas diferenças entre as médias das

Tabela 1. Análise de variância conjunta da produtividade de grãos $\left(\mathrm{kg} \mathrm{ha}^{-1}\right)$ das famílias de feijoeiro-comum e seus genitores.

\begin{tabular}{lrc}
\hline Fonte de variação & Grau de liberdade & Quadrado médio \\
\hline Safras & 1 & $2.530 .414,1^{* *}$ \\
Tratamentos & 395 & $3.274 .088,0^{* *}$ \\
Famílias & 389 & $3.308 .006,9^{* *}$ \\
Famílias da população 1 & 99 & $1.534 .604,9^{* *}$ \\
Famílias da população 2 & 99 & $1.163 .795,5^{* *}$ \\
Famílias da população 3 & 99 & $2.336 .873,3^{* *}$ \\
Famílias da população 4 & 89 & $1.955 .620,6^{* *}$ \\
Tipos de famílias & 3 & $204.757 .453,2^{* *}$ \\
Genitores & 5 & $1.245 .936,7^{*}$ \\
Famílias x genitores & 1 & $220.487,3$ \\
Tratamentos x safras & 395 & $923.528,4^{* *}$ \\
Famílias das populações x safras & 389 & $924.252,0^{* *}$ \\
Famílias da população 1 x safras & 99 & $884.695,4^{* *}$ \\
Famílias da população 2 x safras & 99 & $638.712,7 *$ \\
Famílias da população 3 x safras & 99 & $1.103 .493,4^{* *}$ \\
Famílias da população 4 x safras & 89 & $698.007,8^{* *}$ \\
Tipos de família x safras & 3 & $12.449 .359,9^{* *}$ \\
Genitores x safras & 5 & $727.752,2$ \\
(Famílias x genitores) x safras & 1 & $1.620 .928,8$ \\
Erro efetivo médio & 1.102 & $467.212,3$ \\
\hline CV (\%) & & 24,3 \\
Média & & $2.553,8$ \\
\hline * **Significativo a 5 e 1\% de probabilidade, pelo teste F, respectivamente.
\end{tabular}

famílias de populações diferentes. Os valores do coeficiente de variação $(\mathrm{CV})$ mostraram boa precisão nos experimentos (Marques Júnior, 1997).

Não houve mudança no ranqueamento das médias das famílias de cada população, e as famílias da população 3 foram sempre as mais produtivas (Tabela 2). Isso indica que, mesmo com a interação tipos de famílias $\mathrm{x}$ safras tendo sido significativa (Tabela 1), a maior parte da interação foi de natureza simples, já que não houve alteração na classificação dos genótipos, o que pode ser confirmado pela estimativa de correlação de Pearson entre as médias de produtividade das famílias nas safras avaliadas $(0,66, \mathrm{p}>0,01)$.

As famílias das populações 1,2 e 3 foram, em média, 8,6, 7,6 e 9,5\%, respectivamente, superiores aos genitores que deram origem a cada população (Tabela 2). A existência de variabilidade entre as famílias, detectada nas análises de variância, foi confirmada pelas altas estimativas de variância genética e de herdabilidade (Tabelas 1 e 3), que são indicativos de boa possibilidade de seleção de famílias superiores. Essa possibilidade também foi evidenciada pelos baixos valores encontrados para as relações entre a variância da interação famílias $\mathrm{x}$ safras e a variância genética $\left(\sigma_{\mathrm{GS}}^{2} / \sigma_{\mathrm{G}}^{2}\right)$, quando comparados aos relatados na literatura (Carneiro, 2002). Os valores de $\sigma^{2}{ }_{G S} / \sigma^{2}$ foram $0,38,1,28,0,65,1,03$ e 0,37 , para as famílias sem se considerar a origem da população, e para as famílias das populações 1, 2, 3 e 4 , respectivamente.

Tabela 2. Médias de produtividade de grãos $\left(\mathrm{kg} \mathrm{ha}^{-1}\right)$ dos genitores e das famílias de cada população, na safra das águas, da seca e na análise conjunta ${ }^{(1)}$.

\begin{tabular}{llll}
\hline Genitor ou família & \multicolumn{3}{c}{ Produtividade } \\
\cline { 2 - 4 } & Águas & Seca & Análise conjunta \\
\hline \multirow{2}{*}{ RCI-10 } & $1.978 \mathrm{~A}$ & $1.976 \mathrm{~B}$ & $1.977 \mathrm{~B}$ \\
Z-9 & $2.621 \mathrm{~A}$ & $3.834 \mathrm{~A}$ & $3.228 \mathrm{~A}$ \\
Talismã & $2.924 \mathrm{~A}$ & $2.760 \mathrm{~A}$ & $2.842 \mathrm{~A}$ \\
MAI-18.13 & $1.735 \mathrm{~A}$ & $3.255 \mathrm{~A}$ & $2.495 \mathrm{~B}$ \\
Batatinha & $1.882 \mathrm{~A}$ & $2.846 \mathrm{~A}$ & $2.364 \mathrm{~B}$ \\
B1 & $2.029 \mathrm{~A}$ & $1.762 \mathrm{~B}$ & $1.895 \mathrm{~B}$ \\
\hline Média & 2.195 & 2.739 & 2.467 \\
\hline & & Famílias \\
População 1 & $2.909 \mathrm{~b}$ & $2.743 \mathrm{~b}$ & $2.826 \mathrm{~b}$ \\
População 2 & $2.555 \mathrm{c}$ & $2.631 \mathrm{~b}$ & $2.593 \mathrm{c}$ \\
População 3 & $3.207 \mathrm{a}$ & $3.057 \mathrm{a}$ & $3.132 \mathrm{a}$ \\
População 4 & $1.290 \mathrm{~d}$ & $1.840 \mathrm{c}$ & $1.565 \mathrm{~d}$ \\
\hline Média & 2.522 & 2.588 & 2.555 \\
\hline
\end{tabular}

${ }^{(1)}$ Médias seguidas por letras iguais, nas colunas, não diferem entre si pelo teste de Scott-Knott, a 5\% de probabilidade. 
Os ganhos com a seleção (GS) das dez melhores famílias foram maiores na safra das águas do que na da seca, embora as médias das famílias e os valores de herdabilidade tenham sido semelhantes nas duas safras, o que pode ser explicado pela maior amplitude de variação, pelos maiores valores de limite superior de produtividade, pela maior média das famílias selecionadas e, conseqüentemente, pelo maior valor de diferencial de seleção, observados na safra das águas (Tabela 3).

Considerando-se a seleção de famílias com base nas médias da análise conjunta, os GS foram elevados, com destaque para o GS na população $4(52,2 \%)$ (Tabela 3). Entretanto, essa população apresentou baixa média de produtividade, inclusive em relação às dez melhores famílias, tanto que nenhuma das 50 melhores famílias selecionadas se originou dessa população (Tabelas 2 e 4). A melhor estratégia a se adotar em um programa de melhoramento é selecionar famílias das populações com maior variação e, principalmente, alta produtividade média, pois maior variação genética da população, apenas, não assegura a seleção de genótipos com alta produtividade (Ramalho et al., 1993; Bernardo, 2008), como no caso da população 4. As estimativas de GS, na média da análise conjunta, para as famílias das populações 1,2 e 3 , foram semelhantes $(16,2,14,5$ e $18,7 \%)$, entretanto, merece destaque a seleção de famílias da população 3 , que proporcionou a maior média entre as populações avaliadas, maior média entre as dez melhores famílias selecionadas e herdabilidade ligeiramente superior às demais. Entre as 50 famílias mais produtivas, 34 (68\%) se originaram dessa população.

$\mathrm{Na}$ análise com marcadores moleculares, o marcador BM-156 apresentou alta probabilidade (baixos valores P) de estar ligado a um QTL para produtividade de grãos, na população 3, evidência de que o QTL se expressou somente nessa população (Tabela 4). Pereira et al. (2007) comentam que os alelos desse marcador, presentes nas linhagens Z-9, RCI-10, Talismã e MAI-18.13, são diferentes. Assim, os alelos identificados na população 3 (MAI-18.13 x Z-9) se expressaram de maneira diferente, com relação ao fenótipo produzido, enquanto os alelos presentes na população 2 (RCI-10 x Talismã), embora diferentes, se expressaram de maneira semelhante, já que o marcador apresentou baixa probabilidade de associação ao QTL, nessa população. Para o marcador BM-152, nota-se a mesma tendência de maior associação na população 3 , porém, o alelo encontrado nas linhagens RCI-10 e Z-9 foi o mesmo e, nas linhagens Talismã e MAI-18.13, detectou-se outro alelo. Embora os alelos presentes nas populações 2 e 3 sejam os mesmos para esse marcador, na população 3 eles se expressaram de maneira diferente com relação ao fenótipo produzido, o que explica maior proporção da variação fenotípica observada,

Tabela 3. Estimativas de variância genética $\left(\sigma^{2}\right)$, herdabilidade $\left(h^{2}\right)$, variância da interação famílias $x$ safras $\left(\sigma^{2}{ }_{G S}\right)$, média das dez famílias mais produtivas $(10+)\left(\mathrm{kg} \mathrm{ha}^{-1}\right)$, ganho esperado com a seleção (GS) dessas famílias e número de famílias entre as 50 mais produtivas $(\mathrm{NF})$, relativos à produtividade de grãos, para as famílias no geral e famílias de cada população nas safras das águas, da seca e na análise conjunta.

\begin{tabular}{|c|c|c|c|c|c|c|}
\hline Famílias & $\sigma_{G}^{2}$ & $\mathrm{~h}^{2}$ & $\sigma_{\mathrm{GS}}^{2}$ & Média $(10+)$ & GS (\%) & $\mathrm{NF}(50+)$ \\
\hline & \multicolumn{6}{|c|}{ Águas } \\
\hline Geral & 1.032 .265 & $74(69-79)^{(1)}$ & - & 5.204 & 79,5 & 50 \\
\hline População 1 & 438.124 & $55(40-68)$ & - & 4.638 & 33,1 & 14 \\
\hline População 2 & 205.075 & $37(14-54)$ & - & 3.869 & 19,1 & 5 \\
\hline População 3 & 894.184 & $72(62-79)$ & - & 5.018 & 40,7 & 29 \\
\hline População 4 & 433.477 & $55(39-68)$ & - & 3.147 & 79,1 & 2 \\
\hline & \multicolumn{6}{|c|}{ Seca } \\
\hline Geral & 305.870 & $72(66-73)$ & - & 3.883 & 36,1 & 50 \\
\hline População 1 & 103.143 & $46(29-55)$ & - & 3.538 & 13,5 & 11 \\
\hline População 2 & 79.196 & $40(20-50)$ & - & 3.387 & 11,5 & 8 \\
\hline População 3 & 72.527 & $38(17-48)$ & - & 3.796 & 9,2 & 29 \\
\hline População 4 & 223.906 & $65(53-71)$ & - & 2.857 & 35,8 & 2 \\
\hline & \multicolumn{6}{|c|}{ Conjunta } \\
\hline Geral & 496.615 & 72 & 190.433 & 4.276 & 45,8 & 50 \\
\hline População 1 & 135.398 & 42 & 173.951 & 3.908 & 16,2 & 13 \\
\hline População 2 & 109.392 & 45 & 71.458 & 3.429 & 14,5 & 3 \\
\hline População 3 & 256.954 & 52 & 265.117 & 4.244 & 18,7 & 34 \\
\hline População 4 & 262.002 & 64 & 96.164 & 2.846 & 52,2 & 0 \\
\hline
\end{tabular}

${ }^{(1)}$ Limites inferior e superior para a herdabilidade, a $5 \%$ de probabilidade. 
enquanto na população 2 o marcador explicou uma proporção muito baixa da variação. Essas variação das estimativas de $\mathrm{R}^{2}$ e das probabilidades de associação dos marcadores com o QTL, nas populações, indicam a presença da interação QTL x população, que é relatada freqüentemente (Bernardo, 2002).

Considerando-se um mesmo marcador nas diferentes safras, a associação com QTL também foi variável (Tabela 4) e, novamente, observou-se grande variação nos valores de $R^{2}$ nas safras, o que indica a presença da interação QTL $x$ ambiente, também freqüentemente descrita na literatura (Melo et al., 2004; Rumín, 2005; Bento, 2006). Rodrigues (2004) e Teixeira (2004) relataram que os QTL identificados por esses marcadores são muito influenciados pelo ambiente e que a porcentagem da variação explicada pelos marcadores é pequena, isto evidencia que esses QTL possuem pequenos efeitos ou não estão estreitamente ligados aos marcadores. O marcador BM-156 apresentou as maiores probabilidades de estar ligado a um QTL e as maiores estimativas de $\mathrm{R}^{2}$, além de ter figurado entre os mais estáveis, o que já havia sido relatado por Rodrigues et al. (2007).

Os baixos valores de $\mathrm{R}^{2}$ indicam a baixa eficiência da SAM, no presente trabalho. Por esse motivo, a SAM foi realizada somente para a seleção de famílias da população 3 , que apresentou quatro marcadores polimórficos e com maior estimativa de $\mathrm{R}^{2}$ (Tabela 4). As estimativas de $\mathrm{R}^{2}$ obtidas para esses marcadores por Rodrigues (2004) e Teixeira (2004) variaram de 3,2 a $3,8 \%$, para o marcador BM-152, e foram de 9,2, 6,4 e 3,5\%, para BM-156, U-77935 e X-74919, respectivamente, menores do que as obtidas no presente trabalho para X-74919 e maiores do que as observadas para U-77935, o que está de acordo com a presença da interação QTL x população.
O índice obtido com informações fenotípicas e moleculares, para cada família da população 3 , foi utilizado para a seleção de famílias, e o ganho com a SAM foi estimado por meio do uso dos $\mathrm{R}^{2}$ obtidos nas análises de regressão múltipla "stepwise" $(9,8 \%$ nas águas, $8,8 \%$ na seca e $11,6 \%$ na conjunta), que mostraram, no modelo final, apenas um marcador em todas as safras: o BM-156. Os ganhos obtidos com a SAM foram de pequena magnitude $(0,6 \%$ nas águas, $0,6 \%$ na seca e $0,5 \%$ na análise conjunta) e bem menores do que os obtidos com a seleção fenotípica (Tabela 3 ), o que pode ser explicado pelas baixas estimativas de $\mathrm{R}^{2}$, quando comparadas com as herdabilidades, que foram elevadas. Outro fator que confirma a diferença entre os ganhos obtidos, pelas duas metodologias de seleção, é o de que, entre as 20 famílias mais produtivas, apenas 4 foram selecionadas pela seleção assistida por marcadores.

Os resultados observados no presente trabalho não foram favoráveis para a SAM, já que ela é mais eficiente quando a herdabilidade do caráter é baixa e os marcadores explicam alta proporção da variância aditiva dos caracteres (Lande \& Thompson, 1990). Como a produção de grãos é controlada por grande número de genes de pequeno efeito, para se identificar um grupo de marcadores que expliquem uma maior proporção da variação fenotípica, é necessário utilizar grande número de marcadores ligados a QTL dispersos no genoma (Lande \& Thompson, 1990; Bernardo, 2002; Xu \& Crouch, 2008).

A baixa eficiência da SAM neste trabalho pode, portanto, ser explicada pelo baixo número de marcadores ligados a QTL, em razão do pequeno número de marcadores polimórficos obtidos entre os genitores utilizados, mesmo tendo sido usados microssatélites, que são marcadores com elevado grau de polimorfismo em várias espécies.

Tabela 4. Estimativas de valores $P$ e do coeficiente de determinação $\left(R^{2}\right)$, em percentagem, obtidas nas análises de associação por marcas simples, para os marcadores utilizados nas famílias das populações 2 e 3 , nas safras das águas, seca e na análise conjunta.

\begin{tabular}{|c|c|c|c|c|c|c|c|c|c|c|c|c|}
\hline \multirow[t]{3}{*}{ Marcadores } & \multicolumn{6}{|c|}{ Famílias da população 2} & \multicolumn{6}{|c|}{ Famílias da população 3} \\
\hline & \multicolumn{2}{|c|}{ Águas } & \multicolumn{2}{|c|}{ Seca } & \multicolumn{2}{|c|}{ Conjunta } & \multicolumn{2}{|c|}{ Águas } & \multicolumn{2}{|c|}{ Seca } & \multicolumn{2}{|c|}{ Conjunta } \\
\hline & $\mathrm{P}$ & $\mathrm{R}^{2}$ & $\mathrm{P}$ & $\mathrm{R}^{2}$ & $\mathrm{P}$ & $\mathrm{R}^{2}$ & $\mathrm{P}$ & $\mathrm{R}^{2}$ & $\mathrm{P}$ & $\mathrm{R}^{2}$ & $\mathrm{P}$ & $\mathrm{R}^{2}$ \\
\hline BM-152 & 0,321 & 2,5 & 0,631 & 1,0 & 0,341 & 2,3 & 0,071 & 6,3 & 0,066 & 6,5 & 0,039 & 7,7 \\
\hline BM-156 & 0,124 & 4,7 & 0,504 & 1,6 & 0,196 & 3,7 & 0,025 & 8,0 & 0,008 & 10,4 & 0,016 & 8,1 \\
\hline$X-74949$ & -(1) & - & - & - & - & - & 0,015 & 9,2 & 0,010 & 10,0 & 0,026 & 8,1 \\
\hline U-77935 & - & - & - & - & - & - & 0,065 & 6,2 & 0,283 & 2,9 & 0,070 & 6,0 \\
\hline
\end{tabular}

${ }^{(1)} \mathrm{O}$ marcador não foi utilizado na população. 
O pequeno número de marcadores polimórficos obtidos foi atribuído ao fato de os genitores utilizados serem linhagens melhoradas, todas com grãos do tipo "carioca", o que reduziu a variabilidade e, principalmente, ao fato de o feijoeiro-comum ser uma espécie na qual não se encontra grande polimorfismo naturalmente, nem mesmo quando os genitores são muito contrastantes (Faleiro et al., 2003; Teixeira et al., 2005; Blair et al., 2006a; Rodrigues et al., 2007). Assim, os resultados do presente trabalho confirmam a necessidade de utilização de maior número de marcadores de QTL, para que se aumente a chance de encontrar mais marcadores polimórficos, em populações geneticamente mais homogêneas.

Outra razão para a baixa eficiência da SAM foi a de que as probabilidades estimadas para a ligação dos marcadores aos QTL foram baixas - evidência de que a ligação não foi muito estreita - ou que os QTL foram de pequenos efeitos, o que estaria de acordo com o relatado por Rodrigues (2004) e Teixeira (2004). Considerandose que os genitores são genótipos melhorados e com mesmo tipo de grãos, é razoável assumir-se que alguns QTL estão fixados, principalmente os de maiores efeitos (Bernardo, 2002).

\section{Conclusões}

1. A seleção assistida por marcadores de famílias de feijoeiro-comum com alta produtividade de grãos, originadas de populações elite de melhoramento, que, conseqüentemente, apresentam menor variabilidade, é pouco eficiente quando é utilizado um pequeno número de marcadores que explicam pequena proporção da variação fenotípica.

2. O número de marcadores necessário para se iniciar um trabalho com seleção assistida por marcadores, em programas de melhoramento, é ainda maior do que o recomendado em estudos básicos, nos quais os genitores são muito contrastantes.

\section{Agradecimentos}

Ao Conselho Nacional de Desenvolvimento Científico e Tecnológico, à Coordenação de Aperfeiçoamento de Pessoal de Nível Superior, à Fundação de Amparo à Pesquisa do Estado de Minas Gerais e à Universidade Federal de Lavras, pelo apoio na realização do trabalho.

\section{Referências}

BENTO, D.A.V. Mapeamento de QTL para produção de grãos e seus componentes em uma população de milho tropical. 2006. 133p. Tese (Doutorado) - Escola Superior de Agricultura Luiz de Queiroz, Piracicaba.

BERNARDO, R. Breeding for quantitative traits in plants. Minesota: Stema Press, 2002. 369p.

BERNARDO, R. Molecular markers and selection for complex traits in plants: learning from the last 20 years. Crop Science, v.48, p.1649-1664, 2008.

BLAIR, M.W.; GIRALDO, M.C.; BUENDÍA, H.F.; TOVAR, E.; DUQUE, M.C.; BEEBE, S.E. Microsatellite marker diversity in common bean (Phaseolus vulgaris L.). Theoretical and Applied Genetics, v.113, p.100-109, 2006a.

BLAIR, M.W.; IRIARTE, G.; BEEBE, S. QTL analysis of yield traits in an advanced backcross population derived from a cultivated Andean x wild common bean (Phaseolus vulgaris L.) cross. Theoretical and Applied Genetics, v.112, p.1149-1163, $2006 \mathrm{~b}$

BORÉM, A.; CAIXETA, E.T. (Ed.). Marcadores moleculares. Viçosa: UFV, 2006. 374p.

CARNEIRO, J.E. de S. Alternativas para obtenção e escolha de populações segregantes no feijoeiro. 2002. 134p. Tese (Doutorado) - Universidade Federal de Lavras, Lavras.

CRUZ, C.D.; SCHUSTER, I. GQMOL: aplicativo computacional para análise de dados moleculares e suas associações com caracteres quantitativos. Viçosa: UFV, 2004.

FALEIRO, F.G.; RAGAGNIN, V.A.; MOREIRA, M.A.; BARROS, E.G. de. Use of molecular markers to accelerate the breeding of common bean lines resistant to rust and anthracnose. Euphytica, v.138, p.213-218, 2004.

FALEIRO, F.G.; SCHUSTER, I.; RAGAGNIN, V.A.; CRUZ, C.D.; CORREAA, R.X.; MOREIRA, M.A.; BARROS, E.G. de. Caracterização de linhagens endogâmicas recombinantes e mapeamento de locos de características quantitativas associados a ciclo e produtividade do feijoeiro-comum. Pesquisa Agropecuária Brasileira, v.38, p.1387-1397, 2003.

FREED, R.; EISENSMITH, S.P.; GOETZ, S.; REICOSKY, R.; SMAIL, V.W.; WOLBERG, P. MSTAT-C: a software program for the design, management, and analysis of agronomic research experiments. East Lansing: Michigan State University, 1991.

KNAPP, S.J.; STROUP, W.W.; ROSS, W.M. Exact confidence intervals for heritability on a progeny mean basis. Crop Science, v.25, p.192-194, 1985.

LANDE, R.; THOMPSON, R. Efficiency of marker-assisted selection in the improvement of quantitative traits. Genetics, v.124, p.743-756, 1990.

MARQUES JÚNIOR, O.G. Eficiência de experimentos com a cultura do feijão. 1997. 80p. Tese (Doutorado) - Universidade Federal de Lavras, Lavras.

MATOS, J.W. de. Análise crítica do programa de melhoramento genético do feijoeiro da UFLA no período de 1974 a 2004. 2005. 116p. Tese (Doutorado) - Universidade Federal de Lavras, Lavras. 
MELO, L.C.; SANTOS, J.B. dos; FERREIRA, D.F. QTL mapping for common bean yield in different environments. Crop Breeding and Applied Biotechnology, v.4, p.135-144, 2004.

MENDONÇA, H.A. de; SANTOS, J.B. dos; RAMALHO, M.A.P. Selection of common bean segregating populations using genetic and phenotypic parameters and RAPD markers. Crop Breeding and Applied Biotechnology, v.2, p.219-226, 2002.

MOREAU, L.; CHARCOSSET, A.; GALLAIS, A. Experimental evaluation for several cycles of marker-assisted selection in maize. Euphytica, v.137, p.111-118, 2004.

PAULA JÚNIOR, T.J.; VIEIRA, R.F.; TEIXEIRA, H.; COELHO, R.R.; CARNEIRO, J.E. de S.; ANDRADE, M.J.B. de; REZENDE, A.M. (Ed.). Informações técnicas para o cultivo do feijoeirocomum na região central brasileira: 2007-2009. Viçosa: Epamig, 2008. 180p. (Epamig. Série Documentos, 42).

PEREIRA, H.S.; SANTOS, J.B. dos; ABREU, A. de F.B.; COUTO, K.R. Informações fenotípicas e marcadores microssatélites de QTL na escolha de populações segregantes de feijoeiro. Pesquisa Agropecuária Brasileira, v.42, p.707-713, 2007.

RAMALHO, M.A.P.; FERREIRA, D.F.; OLIVEIRA, A.C. de. Experimentação em genética e melhoramento de plantas. Lavras: Ufla, 2000. 326p.

RAMALHO, M.A.P.; SANTOS, J.B.; ZIMMERMANN, M.J. de $O$. Genética quantitativa em plantas autógamas: aplicações ao melhoramento do feijoeiro. Goiânia: UFG, 1993. 271p.

RODRIGUES, T.B. Efeito da seleção natural em alelos microssatélites (SSR) do feijoeiro e associação com QTL de caracteres agronômicos. 2004. 90p. Dissertação (Mestrado) Universidade Federal de Lavras, Lavras.

RODRIGUES, T.B.; SANTOS, J.B. dos; RAMALHO, M.A.P.; AMORIM, E.P.; SILVA, N.O. Identificação de QTL em feijoeiro por meio de marcadores SSR influenciados pela seleção natural. Ciência e Agrotecnologia, v.31, p.1351-1357, 2007.

RUMÍN, G.C.R. Análise da interação genótipo $\mathbf{x}$ ambientes assistida por marcadores moleculares em milho (Zea mays L.). 2005. 212p. Tese (Doutorado) - Escola Superior de Agricultura Luiz de Queiroz, Piracicaba.

SCHUSTER, I.; CRUZ, C.D. Estatística genômica aplicada a populações derivadas de cruzamentos controlados. Viçosa: UFV, 2004. 568p.

STROMBERG, L.D.; DUDLEY, J.W.; REFENER, G.K. Comparing conventional early generation selection with molecular markerassisted selection in maize. Crop Science, v.34, p.1221-1225, 1994.

TEIXEIRA, F.F. Mapeamento de QTL para caracteres do feijoeiro por meio de microssatélites. 2004. 189p. Tese (Doutorado) - Universidade Federal de Lavras, Lavras.

TEIXEIRA, F.F.; SANTOS, J.B. dos; RAMALHO, M.A.P.; ABREU,A. de F.B.; GUIMARÃES, C.T.; OLIVEIRA,A.C. de.QTL mapping for angular leaf spot in common bean using microsatellite markers. Crop Breeding and Applied Biotechnology, v.5, p.272-278, 2005.

VENCOVSKY, R.; BARRIGA，P. Genética biométrica no fitomelhoramento. Ribeirão Preto: Sociedade Brasileira de Genética, 1992. 486p.

XU, Y.; CROUCH, J.H. Marker-assisted selection in plant breeding: from publications to pratice. Crop Science, v.48, p.391-407, 2008.

YOUSEF, G.G.; JUVIK, J.A. Comparison of phenotypic and marker-assisted selection for quantitative traits in sweet-corn. Crop Science, v.41, p.645-655, 2001.

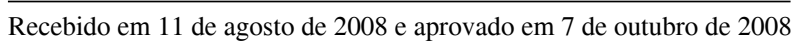

